\author{
Reply \\ HOLLY K. EISSLER \\ Institute of Geophysics and Planetary Physics, Scripps Institution of Oceanography \\ University of California, San Diego, La Jolla
}

\title{
Hiroo KANAMORI
}

Seismological Laboratory, California Institute of Technology, Pasadena

We showed that the long-period seismic radiation from the November 29, 1975, Kalapana Hawaii earthquake, which involved seaward displacement of the south flank of Kilauea volcano, was best explained by invoking a near-horizontal single force as the kinematic source of the earthquake [Eissler and Kanamori, 1987]. In particular, the azimuthal dependence of 100-s Love surface waves is difficult to explain by a conventional double-couple source. The unusual Love wave pattern was noted by Ando [1979] but not explained until our suggestion of the single-force source model. As explained in our paper, a two-lobed Love wave radiation pattern could be produced by a double-couple source only if the fault dip angle $\delta$ is very nearly zero. At $\delta=2.5^{\circ}$, the $\sin \phi$ (two-lobed) and $\sin 2 \phi$ (four-lobed) terms already give equal contributions to the radiation pattern, and when $\delta=4.5^{\circ}$, the azimuthal pattern is essentially four-lobed. Thus the only geometry that produces a two-lobed radiation pattern with the double-couple source is that of a very flat fault plane, and the fault plane must remain flat throughout the rupture process. The single-force model does not have this restriction, and the force dip can be inclined to horizontal and still produce the observed two-lobed pattern. There is also another problem. If the fault plane is purely horizontal at zero depth, no Love wave energy is produced by the double-couple source. Thus, as the fault dip approaches zero for shallow earthquakes, the seismic moment must become very large to explain any appreciable Love wave energy. For example, the seismic moment required to generate the Love wave amplitudes observed in the Kalapana earthquake with the double-couple source increases by a factor of 4 as the fault angle decreases from $10^{\circ}$ to $0^{\circ}$ for a source depth of $10 \mathrm{~km}$. Ando [1979] rejected models with $\delta=0$ because the seismic moment required to match the observed surface wave amplitudes would produce crustal deformation much larger than that observed. He found that a dip angle of $20^{\circ}$ best fits the observed subsidence and tsunami patterns.

Wyss and Kovach [this issue] refer to Figure 4 of our paper, which is simply a reproduction of Ando's [1979] results, and argue that the radiation pattern can be interpreted as either two-lobed or four-lobed. Ando [1979] measured gross time domain Love wave amplitudes from as many World-Wide Standard Seismograph Network (WWSSN) stations as possible of $G_{1}, G_{2}$, and $G_{3}$ passages. In Eissler and Kanamori [1987] we improved the Love wave pattern in several ways. First, we looked only at 100 -s spectral data, eliminating shorter periods perhaps affected by heterogeneities and source ef-

\section{Copyright 1988 by the American Geophysical Union.}

Paper number 8B6142.

$0148-0227 / 88 / 008 B-6142 \$ 02.00$ fects. We restricted ourselves to the $G_{2}$ passage, as $G_{1}$ can be contaminated by multiple $S$ phases and $G_{3}$ is approaching noise level at most stations. We used several analog records from HGLP (high gain long period) instrumentation, not used by Ando [1979], which had improved long-period response at $100 \mathrm{~s}$. To assure the best possible data from WWSSN stations, we used only records with higher gains. The appropriate reference to our results is Figure 7 of Eissler and Kanamori [1987], which shows a clear and unmistakable radiation maximum at the azimuth where the four-lobed radiation pattern of the double-couple source predicts a node. Recent work with more HGLP data shows that the two-lobed pattern persists out to periods of at least $225 \mathrm{~s}$.

The two-lobed Love wave pattern is an important feature of the Kalapana earthquake and cannot be dismissd as unreliable because of fault complexity, as Wyss and Kovach attempt to do. Although we expect seismic radiation at short periods to show the effects of rupture complexity, long-period ( $T>50 \mathrm{~s}$ ) waves have been successfully used to correctly determine the overall source geometry of earthquakes for many years.

Harvey and Wyss [1986] appealed to variations in fault orientation to explain the complex nature of accelerograms recorded at two stations from the Kalapana earthquake. Their results are reproduced in Figure 2 of the comment by Wyss and Kovach. Note that several of the subevents have dip angles of about $10^{\circ}$ or greater, which would certainly dominate the radiation pattern of surface waves, causing the Love wave radiation pattern to be four-lobed, if this were representative of the overall source process of the earthquake. Yet the observed pattern is clearly not four-lobed. In proposing the single-force model, we acknowledged that the first motion data, or short-period radiation such as the accelerograms used to infer these subevents, may very well be best explained by a conventional double-couple source. Our paper addressed the long-period radiation only.

Wyss and Kovach misunderstood the point in our statement that the south flank of Kilauea is mobile and had undergone extensions of several meters in the last century. We have no disagreement with the observation of short-term contraction events on Kilauea's south flank that may reflect cyclical changes in the volcano's magmatic system. We would expect to see crustal shortening and compression prior to the earthquake, regardless of whether it was gravity-driven or magmadriven, since there will always be a frictional force on the failure plane or planes that must be overcome. Our point is that the long-term deformational character of the south flank shows extension, or seaward displacement. We do not think we misinterpreted the facts presented in the detailed deformation study of Swanson et al. [1976, p. 13] where they state 
that

Long-term horizontal displacements, as measured over periods of years to decades, are of considerable magnitude at Kilauea.... The entire south flank moved southeastward in a direction almost exactly perpendicular to the east rift zone and the Koae fault system; this direction is more nearly perpendicular to the trend of the rift zone as a whole than to individual fissures within the rift zone.

Swanson et al. [1976] repeatedly describe the south flank as mobile to some depth that may be between 5 and $8 \mathrm{~km}$, or a gradual decrease in mobility with depth. In a study of the ground deformation from the Kalapana earthquake, Lipman et al. [1985] showed that the vertical displacements everywhere on the south flank were negative, that is, the area subsided. Many researchers have appealed to the volcano-oceanic crust interface, presumably lubricated by the accumulation of deep sea sediments prior to the development of the volcano, as the fault plane of the Kalapana earthquake or the sole of the large-scale block slump [Nakamura, 1982; Furumoto and Kovach, 1979; Crosson and Endo, 1981; Lipman et al., 1985]. Presumably, this interface dips gently under the volcanic load, so that a rigid displacement of the south flank along it would have a reverse sense. However, if the overall event were a low-angle thrust, some uplift should have been observed on the south flank. In fact, our model is very similar to Lipman et al's [1985] interpretation of the deformation data: regardless of the details or location of the initial seismic event, a largescale gravity slump is responsible for the overall displacement (and hence long-period seismic waves). We envision large-scale gravity slumping of the south flank on many subsidiary slide planes that may merge with a basal plane producing block rotations, such as shown by Lipman et al. [1985, Figure 20], Holcomb [1987, Figure 12.61], or Hill and Zucca [1987, Figure 37.10]. Whether the basal plane coincides with the lubricated interface is not known, but it is an appealing idea.

As we discussed above, we believe that the two-lobed Love wave radiation pattern is real and can be best explained by a single-force model. Obviously, the actual source process is likely to be more complex than one that can be represented by a simple single force. However, more complicated kinematic source models were not warranted because of the limited quality and quantity of the data available to us. The interpretation of the data from the Kalapana earthquake is not as clear as for the classic landslide associated with the eruption of Mount St. Helens, discussed by Kanamori and Given [1982]. Improvement of the source model may be possible in the future; for example, Kawakatsu [1987] has used digital HGLP data from the Kalapana earthquake at a few stations only recently compiled by the U.S. Geological Survey. These data are probably better than the analog records used by Eissler and Kanamori [1987]. Further analysis of the improved data set may be able to resolve more details of the source process associated with the 1975 Kalapana earthquake, but we believe that our primary conclusion that the long-period Love wave radiation pattern can be best explained by the single force will remain unchanged. We thank Wyss and Kovach for this opportunity to clarify our results.

\section{REFERENCES}

Ando, M., The Hawaii earthquake of November 29, 1975: Low dip angle faulting due to forceful injection of magma, $J$. Geophys. Res., 84, 7616-7626, 1979.

Crosson, R. S., and E. T. Endo, Focal mechanisms and locations of earthquakes related to the 29 November 1975 Kalapana, Hawaii earthquake: The effect of structural models, Bull. Seismol. Soc. Am., $71,713-729,1981$.

Eissler, H. K., and H. Kanamori, A single-force model for the 1975 Kalapana, Hawaii, earthquake, J. Geophys. Res. 92, 4827-4836, 1987.

Furumoto, A. S., and R. L. Kovach, The Kalapana earthquake of November 29, 1975: An intra-plate earthquake and its relation to geothermal processes, Phys. Earth Planet. Inter., 18, 197-208, 1979.

Harvey, D., and M. Wyss, Comparison of a complex rupture model with the pre-cursor asperities of the 1975 Hawaii $M_{S}=7.2$ earthquake, Pure Appl. Geophys., 124, 957-973, 1986.

Hill, D. P., and J. J. Zucca, Geophysical constraints on the structure of Kilauea and Mauna Los volcanoes and some implications for seismomagmatic processes, Volcanism in Hawaii, U.S. Geol. Surv. Prof. Pap., 1350, 903-934, 1987.

Holcomb, R. T., Eruptive history and long-term behavior of Kilauea Volcano, Volcanism in Hawaii, U.S. Geol. Surv. Prof. Pap., 1350, 261-350, 1987.

Kanamori, H., and J. W. Given, Analysis of long-period seismic waves excited by the May 18, 1980, eruption of Mount St. Helens: A terrestial monopole?, J. Geophys. Res., 87, 5422-5432, 1982.

Kawakatsu, H., Centroid single force inversion of seismic waves generated by landslides (abstract), Eos Trans. AGU, 68, 1353, 1987.

Lipman, P. W., J. P. Lockwood, R. T. Okamura, D. A. Swanson, and K. M. Yamashita, Ground deformation associated with the 1975 magnitude 7.2 earthquake and resulting changes in activity of Kilauea volcano, Hawaii, U.S. Geol. Surv. Prof. Pap., 1276, 1-45, 1985.

Nakamura, K., Why do long rift zones develop better in Hawaiian volcanoes - A possible role of thick sediments, in Proceedings, International Association of Volcanology and Chemistry of the Earth's Interior 1980 Symposium on the Activity of Ocean Volcanoes, Ponta Delgada, Azores, Universidade dos Acores, pp. 59-73, International Association of Volcanology and Chemistry of the Earth's Interior, Rome, 1982

Swanson, D. A., W. A. Duffield, and R. S. Fiske, Displacement of the south flank of Kilauea volcano: The result of forceful intrusion of magma into the rift zones, U.S. Geol. Surv. Prof. Pap., 963, 1-39, 1976.

Wyss, M., and R. L. Kovach, Comment on "A single-force model for the 1975 Kalapana. Hawaii, earthquake" by Holly K. Eissler and Hiroo Kanamori, J. Geophys. Res., this issue.

H. K. Eissler, Institute of Geophysics and Planetary Physics, Scripps Institution of Oceanography, University of California, San Diego, La Jolla, CA 92093.

H. Kanamori, Seismological Laboratory, California Institute of Technology, Pasadena, CA 91125.

(Received March 29, 1988 accepted April 11, 1988.) 